\title{
Quantitative sputum cell counts to monitor bronchitis: A qualitative study of physician and patient perspectives
}

\author{
Liesel D'silva MD ${ }^{1 *}$, Helen Neighbour MB BS PhD MRCP(UK) ${ }^{1 *}$, Amiram Gafni PhD², Katherine Radford MSc ${ }^{1}$, \\ Frederick E Hargreave MD FRCP ${ }^{* *}$, Parameswaran Nair MD PhD FRCP FRCPC ${ }^{1}$
}

L D'silva, H Neighbour, A Gafni, K Radford, FE Hargreave, P Nair. Quantitative sputum cell counts to monitor bronchitis: A qualitative study of physician and patient perspectives. Can Respir J 2013;20(1):47-51.

Many common diseases affecting the airways are characterized by airway inflammation. The measurement of this inflammation has a significant role in the management of these diseases. Quantitative sputum cell counts provide a measurement of the type and severity of inflammation present. Sputum cell counts are used in routine clinical practice in some centres but their use is not widespread. The present study used a standardized questionnaire to determine both patients' and physicians' attitudes toward the use of sputum cell counts. The use of sputum cell counts was well accepted by patients and physicians. Ninety per cent of patients were satisfied with the test. Sixty per cent of family physicians were satisfied with the test and $80 \%$ were in favour of it being funded by the government. The authors recommend more widespread use of sputum cell counts to guide the management of airway diseases.

Key Words: Asthma; Bronchitis; Patient satisfaction; Sputum cell counts; Willingness to pay

$\Delta$ irway inflammation is an important component of all diseases of Athe airways, including asthma, chronic obstructive airway disease, emphysema, bronchiectasis and chronic cough $(1,2)$; however, the importance of inflammation in its treatment is generally not acknowledged in consensus documents $(3,4)$. Methods of measuring airway inflammation, such as exhaled nitric oxide (5) and quantitative sputum cell counts (6-8), have reached clinical practice but are not widely used (9). In contrast to exhaled nitric oxide (10), the use of induced sputum cell counts has been shown to be successful in reducing exacerbations of disease $(11,12)$ and health care costs $(12)$. Despite this, its application has been established in clinical practice in only a few cities in Canada: Quebec City and Montreal (Quebec), Hamilton (Ontario) and Calgary (Alberta) (9). The use of sputum cell counts has received criticism in the literature with the suggestion that the procedure is time consuming and should only be reserved for a specific subset of patients being considered for treatment with antieosinophil therapies such as anti-interleukin-5 (13). Potential reasons for this include the perceived unpleasantness and difficulty of the procedure, and the skepticism related to patient and physician satisfaction. Therefore, we assessed patient satisfaction and strength of satisfaction based on patients' willingness to pay for sputum induction (14), and the acceptability and physician satisfaction with quantitative sputum cell counts and its impact on clinical practice in Canada. The use of patient-reported outcomes is becoming increasingly important - the United States Food and Drug Administration recently released guidelines on the use of patient-reported outcomes in medical product development, which has implications for the conduct of research (15).

\section{La numération cellulaire quantitative dans les expectorations pour surveiller la bronchite : une étude qualitative du point de vue des médecins et des patients}

\begin{abstract}
De nombreuses maladies courantes des voies aériennes se caractérisent par une inflammation des voies aériennes. La mesure de cette inflammation joue un rôle important dans la prise en charge de ces maladies. La numération cellulaire dans les expectorations fournit une mesure du type et de la gravité de l'inflammation. Certains centres recourent à la numération cellulaire dans les expectorations en pratique clinique habituelle, mais son utilisation n'est pas généralisée. La présente étude faisait appel à un questionnaire standardisé pour déterminer les attitudes des patients et des médecins à l'égard de son utilisation. Son recours était bien accepté des patients et des médecins. Quatre-vingt-dix pour cent des patients étaient satisfaits par le test. Soixante pour cent des médecins de famille l'étaient également, et 80 \% étaient d'accord pour qu'il soit financé par le gouvernement. Les auteurs recommandent une utilisation plus généralisée de la numération cellulaire dans les expectorations pour orienter la prise en charge des maladies des voies aériennes.
\end{abstract}

Patient satisfaction is also now considered to be a quality of care indicator $(16,17)$ and is associated with adherence to medical treatment plans (18). It has recently been recommended that more importance be placed on patient satisfaction in the management of another chronic condition - heart failure (19). Patient satisfaction is likely to receive more emphasis in the management of chronic disease in the future. In addition, if referring physicians consider the test to be useful in the management of their patients, usage will increase. We believe that the information presented in the present article is essential to have sputum cell differential counts widely accepted by both physicians and patients. Once this is achieved, it will increase the likelihood of routine use in clinical practice.

\section{Setting}

\section{METHODS}

The project was performed at the Firestone Institute for Respiratory Health, a tertiary respirology centre located in Hamilton.

\begin{abstract}
Assessment of patient satisfaction and willingness to pay for sputum induction

Survey instrument: Patient satisfaction was assessed using a standardized questionnaire. The questionnaire was developed after interviewing patients who had undergone sputum induction and respirologists who referred patients for sputum induction. Information based on a literature review was also included. The hospital research ethics board approved the questionnaire. A research fellow or a pulmonary function technologist administered the questionnaire to patients who
\end{abstract}

*Authors contributed equally to the preparation of the manuscript; **Deceased

${ }^{1}$ Firestone Institute for Respiratory Health, St Joseph's Healthcare and Department of Medicine; ${ }^{2}$ Centre for Health Evaluation and Policy

Analysis, Department of Clinical Epidemiology and Biostatistics, McMaster University, Hamilton, Ontario

Correspondence: Dr Parameswaran Nair, Firestone Institute for Respiratory Health, St Joseph's Healthcare, 50 Charlton Avenue East, Hamilton, Ontario L8N 4A6. Telephone 905-522-1155 ext 35044, fax 905-521-6183, e-mail parames@mcmaster.ca 
visited the clinic for routine sputum induction. The purpose of the questionnaire was explained to the patient and written informed consent was obtained. The questionnaire was designed to collect information in three domains including sociodemographic status (eight questions), the convenience of attending the clinic for the sputum test (six questions) and experience with the procedure of sputum induction (eight questions). For most of the questions, the patient was required to circle the most relevant answer and usually completed the questionnaire within $20 \mathrm{~min}$. Overall satisfaction was assessed using a 6-point Likert scale (1 to 6), with lower scores indicating greater satisfaction. The patients' 'willingness to pay' was assessed using a bidding algorithm, after presenting them with data from a previous two-year randomized controlled study (11) to explain the advantages of treating airway disease using induced sputum cell counts compared with current practice and was made clear that the valuation exercise was hypothetical. A sputum induction costs $\operatorname{CAD} \$ 250$, which includes spirometry during induction, technologist's time, reagents required for processing the sputum sample, professional fee for supervision and interpretation of the report, and laboratory maintenance. Therefore, $\$ 250$ was chosen as the initial figure in the willingness-to-pay bidding algorithm. The bidding continued by either increasing or decreasing by $50 \%$ until two values that were 20 units apart were reached. The final figure corresponded to the average of the two values.

Study population and sample size: Male and female patients 18 to 82 years of age who had undergone at least one sputum induction participated in the present study. Based on sample size for proportions, to be $95 \%$ certain that the true population proportion estimated by the sample was between $40 \%$ and $60 \%$ (10\% CI), 96 interviews would need be conducted to meet these precision requirements. The 'willingness to pay' was assessed in a subset of patients who underwent at least two sputum inductions.

Assessment of physician satisfaction with quantitative sputum cell counts and the impact on their clinical practice

Survey instrument: The questionnaire was developed on the basis of a literature review and expert opinion. A review of the English literature was conducted using the PubMed database and the following index terms: "satisfaction", "provider satisfaction", "satisfaction questionnaires", "asthma" and "sputum cell counts". The team of respirologists at the Firestone Institute for Respiratory Health (Hamilton, Ontario) assessed the 21-item questionnaire for face validity. The response format, structure, relevance, appropriateness and clarity of each of the questions were evaluated on a scale of 0 (strongly disagree) to 6 (strongly agree). Based on feedback, the items were scaled and reduced to 18 items. The 18 items scoring 5 or 6 by at least $70 \%$ of the respondents were selected. Using a 7-point numerical scale, these items were divided into four categories (need for induced sputum, logistics, usefulness and impact) to form the questionnaire.

The questionnaire was mailed to 300 family physicians in the Hamilton-Wentworth (Ontario) region who received a copy of the sputum report from August 2004 to January 2006. With each questionnaire, a cover letter explaining the purpose of the study, ensuring anonymity of the responder and providing instructions on how to respond to the survey, and a stamped postage-paid return envelope was enclosed. Two additional mailings separated by four to five weeks were targeted to recipients who had not responded to the initial survey.

To obtain information from specialists in the field, feedback from specialists in respirology and allergy was also sought. Another questionnaire specific to this group of physicians was mailed to 300 specialists across Canada. A cover letter explaining the purpose of the survey was included. Two additional mailings were sent to individuals who had not responded to the initial survey.

\section{Statistical analysis}

Descriptive statistics were used to summarize the items in the questionnaire. Willingness to pay was reported as median (first quartile [Q1], third quartile [Q3]). Regression analysis using a stepwise model was used to examine the relationship between willingness to pay and demographic variables such as age, marital status, health status, employment, annual income and satisfaction level with sputum induction; $\mathrm{P}<0.05$ was considered to be statistically significant. All statistical analyses were performed using SPSS version 13 (IBM Corporation, USA) for Windows (Microsoft Corporation, USA).

\section{Patient questionnaire}

\section{RESULTS}

Respondent demographics: A total of 101 patients completed the questionnaire. The mean age of the respondents was 57 years (range 18 to 82 years); $51 \%$ were men and $67 \%$ were married. The majority of patients had asthma $(57 \%)$, while the remaining had chronic airflow limitation $(27 \%)$, bronchiectasis $(6 \%)$ or chronic cough $(4 \%)$, and $6 \%$ had other diseases such as unexplained breathlessness on exertion, nonobstructive pulmonary disease and peripheral eosinophilia. A diagnosis was not available for two patients. Most of the patients had less than 12 years of formal education (41\%), 39\% were retired, 30\% were in full time employment, $33 \%$ had an annual income of between $\$ 20,001$ and $\$ 40,000$, and $42 \%$ self-rated their health status as 'good', while $8 \%$ rated their health status as 'poor'.

Satisfaction rating of sputum induction: The majority (71\%) of respondents found it convenient to attend the clinic for sputum induction (Table 1) and $90 \%$ were satisfied with the test (Table 2). Patients 51 to 82 years of age were significantly more satisfied compared with younger respondents. Sex and health status did not affect satisfaction with sputum cell counts.

Willingness to pay: The willingness to pay was assessed in 82 patients who underwent at least two sputum inductions. The total median (Q1, Q3) amount of money patients were willing to pay for the test was $\$ 125$ (\$52, \$300). The patients who were very satisfied (59\%) were willing to pay a mean $( \pm$ SD) of $\$ 217 \pm 200$ while most of the patients $(46 \%)$ agreed to pay up to $\$ 100$ (Figure 1). Respondents with a higher annual income were willing to pay up to $\$ 27$ more for sputum induction (95\% CI 3.66 to 50.23; $\mathrm{P}=0.024)$ compared with individuals with lower annual incomes. Age, marital status, health status, employment and overall satisfaction level with sputum induction did not influence patients' willingness to pay for sputum induction.

\section{Family physician questionnaire}

Response rate: A total of 160 (53\%) family physicians responded to the questionnaire, $52 \%$ after the first mailing, 32\% after the second and $16 \%$ after the third. Of these, 52 were ineligible. The ineligible family physicians included five who retired from clinical practice; 12 returned the survey but refused to complete it without giving a reason; 13 did not directly refer patients for sputum induction; one was a pediatrician who believed that it was inappropriate to complete the questionnaire; 10 could not recall sending a patient for the test; two believed that the wait time to obtain an appointment was more than one week and, therefore, refused to complete the questionnaire; and nine could not be contacted due to a change in address. The remaining 108 family physicians formed the basis of the present report.

Satisfaction with quantitative sputum cell counts: Items inquiring about the safety and success of sputum induction, time to obtain an appointment for the test, and understanding and valuing the information from the report had mean scores of $\geq 4$ in more than $60 \%$ of the respondents - an indication of provider satisfaction; however, approximately $50 \%$ of the physicians were not satisfied with the delay of more than seven days in receiving the report and would prefer to receive it within three days (Tables 3 and 4).

Impact on clinical practice: More than $60 \%$ of the respondents agreed that the test provided them with information that could not be obtained clinically; helped in deciding the best possible treatment for their patients; was a useful procedure in managing airway diseases, especially during exacerbations; and served as a guide to adjust corticosteroid treatment. Overall, family physicians believed that sputum cell counts achieved worthwhile results for their patients and that the procedure should be funded by the Ontario Health Insurance Plan 
TABLE 1

Factors related to convenience of reporting for sputum induction

\begin{tabular}{lc}
\hline Sputum tests performed per patient* & 4 (1 to 100) \\
Cost of travel to and from the centre ${ }^{\star}, \$$ & 0 (0 to 45) \\
Parking charge per visit*, \$ & 0 (0 to 12) \\
Convenience of attending the clinic for the sputum test, \% & 71 \\
Convenient to come for the test & 28 \\
Previous home arrangement had to be made & \\
$\quad$ before coming for the test & 1 \\
Timing was unsuitable & 6 \\
Loss of income when you report for the test, \% & 86 \\
Always & 7 \\
None & 1 \\
Occasionally & \\
Not in paid employment & 29 \\
Timing of the sputum test, \% & 52 \\
Arranged before clinic visit & 8 \\
Arranged at the same time of clinic visit & 1 \\
Arranged after clinic visit & 6 \\
Arranged at the same time or after clinic visit & 2 \\
Arranged at the same time or before clinic visit & 3 \\
Arranged before or after clinic visit & \\
\hline
\end{tabular}

*Data presented as median (minimum to maximum) unless otherwise indicated

(OHIP), a government-run health insurance plan for the residents of Ontario (Tables 3 and 4).

Questionnaire for specialists

Thirty-three specialists (94\% respirologists, 3\% respirologist and otolarygologists, and $3 \%$ pediatricians) in practice for a mean of $18 \pm 9.6$ years caring for patients with airway disease $(60 \pm 22 \%)$ and chronic cough $(28 \pm 26 \%)$ completed the questionnaire (10\% response rate). Of these, $70 \%$ and $24 \%$ were in hospital and community practice, respectively, while the remaining were practicing in a hospital and in the community. Although 55\% of the specialists were aware of the availability of quantitative sputum cell counts, $19 \%$ used the service less than once per week, $6 \%$ once or twice per week, $3 \%$ three to five times per week and $6 \%$ more than five times per week.

\section{DISCUSSION}

The survey used in the present study demonstrated that the use of quantitative sputum cell counts to guide the management of airway diseases was well accepted by patients and clinicians. Ninety per cent of the patients were satisfied and were willing to pay a total estimated median amount of $\$ 125$ for sputum induction. More than $60 \%$ of the family physicians were satisfied with the test and more than $80 \%$ were in favour of the test being funded by OHIP.

The data were collected from more than 100 patients, $70 \%$ of whom had undergone up to 10 sputum inductions, $14 \%$ up to 20 and the remaining up to 100 over the past few years. We assessed the willingness to pay in patients who had undergone at least two sputum inductions. By this, we were certain that patients understood the value of the test.

One of the limitations of the present study was the low response rate to the physicians' survey questionnaire. This occurred despite several measures taken to explain the purpose of the study, ensure anonymity and facilitate response to the mailed questionnaire. Other contributing factors could be lack of financial or nonfinancial incentives (20), no telephone call reminders, excessive mailing interfering with busy practice (21), or the mere lack of interest because the patient was referred by the respiriologist and not the family physician. We expected a reply from 150 physicians who had received sputum reports for at least two or more patients; therefore, responses from 108 of 150 yielded a high response rate of $71 \%$.
TABLE 2

Experiences of patients undergoing sputum induction

\begin{tabular}{|c|c|}
\hline \multicolumn{2}{|l|}{ Behaviour of medical staff } \\
\hline Always courteous & 96 \\
\hline Usually courteous & 3 \\
\hline Occasionally courteous & 1 \\
\hline \multicolumn{2}{|l|}{ Explanation of the procedure by the medical staff } \\
\hline Always explain the procedure & 87 \\
\hline Usually explain the procedure & 10 \\
\hline Occasionally explain the procedure & 3 \\
\hline \multicolumn{2}{|l|}{ Symptoms caused by sputum induction } \\
\hline No increased symptoms & 58 \\
\hline Chest tightness & 4 \\
\hline Cough & 19 \\
\hline Wheeze & 3 \\
\hline Shortness of breath & 7 \\
\hline Shortness of breath and chest tightness & 3 \\
\hline Cough and wheeze & 1 \\
\hline Cough and chest tightness & 1 \\
\hline Increase in all symptoms & 2 \\
\hline \multicolumn{2}{|l|}{ Necessity of the procedure } \\
\hline No (the patient could cough up sputum on his/her own) & 15 \\
\hline Yes (the patient could not cough up sputum on his/her own) & 85 \\
\hline \multicolumn{2}{|l|}{ Taste of hypertonic saline } \\
\hline Unacceptable & 14 \\
\hline Acceptable & 86 \\
\hline \multicolumn{2}{|l|}{ Test duration } \\
\hline$<45 \min$ & 75 \\
\hline $1 \mathrm{~h}$ & 22 \\
\hline$>1 \mathrm{~h}$ & 3 \\
\hline \multicolumn{2}{|l|}{ Total time spent in the laboratory } \\
\hline Unduly long & 6 \\
\hline Not unduly long & 94 \\
\hline \multicolumn{2}{|l|}{ Overall satisfaction on the 6-point Likert scale } \\
\hline Very satisfied & 64 \\
\hline Moderately satisfied & 26 \\
\hline Slightly satisfied & 10 \\
\hline
\end{tabular}

Data presented as \%

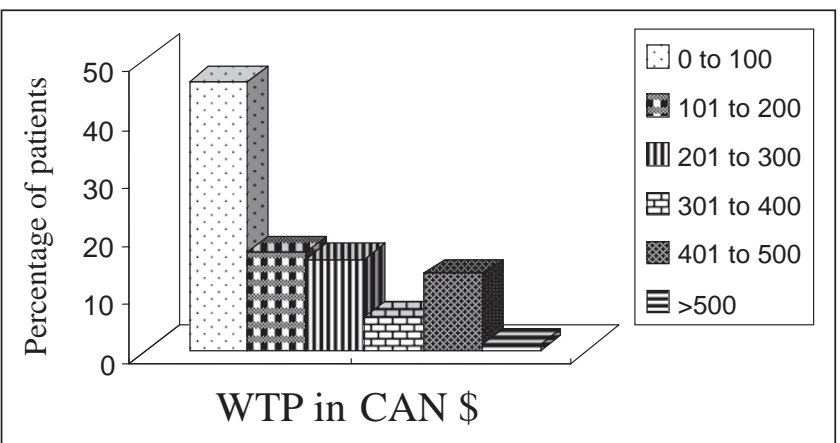

Figure 1) The frequency distribution of the willingness to pay (WTP) for sputum induction. The bars indicate the percentage of patients willing to pay for sputum induction. The values on the $x$ axis are expressed in different ranges. There was only one patient who agreed to pay $\$ 1,000$

Other studies have examined physicians' beliefs and prescribing habits, patients' experiences with asthma, doctor-patient communication, satisfaction with asthma medications and interest in new-onset asthma (22), cost effectiveness in occupational asthma (23), perceptions of chronic obstructive pulmonary disease (COPD) severity, quality of life, attitudes about COPD, health insurance barriers to COPD care, sources of information and knowledge about COPD diagnosis and treatment (24). To our knowledge, the present questionnaire-based 
TABLE 3

Descriptive statistics of items in the physician satisfaction questionnaire

\begin{tabular}{|c|c|c|c|c|}
\hline & \multirow[b]{2}{*}{ Respondents, $\mathrm{n}$} & \multicolumn{3}{|c|}{ Score } \\
\hline & & Mean \pm SD & Minimum & Maximum \\
\hline $\begin{array}{l}\text { Sputum induction is a non invasive usually successful and safe method to assess the type of airway } \\
\text { inflammation }\end{array}$ & 108 & $4.4 \pm 1.1$ & 1 & 6 \\
\hline $\begin{array}{l}\text { I feel my patient understands the need to have a sputum test to assess the type of airway inflammation } \\
\text { than not to have one }\end{array}$ & 102 & $3.6 \pm 1.3$ & 0 & 6 \\
\hline I usually receive the sputum report within 3 to 7 days after the procedure is done & 104 & $3.6 \pm 1.5$ & 0 & 6 \\
\hline I understand the information that I get from this report & 107 & $4.2 \pm 1.3$ & 0 & 6 \\
\hline I value the information that I get from this report & 104 & $4.5 \pm 1.2$ & 0 & 6 \\
\hline The different types of airway inflammation are clear to me after reviewing the sputum reports & 107 & $3.8 \pm 1.4$ & 0 & 6 \\
\hline Sputum induction provides me with information that I am unable to obtain clinically & 107 & $4.1 \pm 1.3$ & 0 & 6 \\
\hline I feel I am achieving worthwhile results through my referral for sputum induction & 106 & $4.1 \pm 1.3$ & 0 & 6 \\
\hline The sputum report usually assists in arriving at the best possible treatment for my patient & 106 & $4.2 \pm 1.2$ & 0 & 6 \\
\hline Sputum induction should be a part of routine management for patients with airway disease & 105 & $4 \pm 1.4$ & 0 & 6 \\
\hline This procedure should be funded by the Ontario Health Insurance Plan & 102 & $4.8 \pm 1.3$ & 0 & 6 \\
\hline Percentage of patients with airway disease referred for quantitative sputum cell counts & 86 & $3 \pm 1.7$ & $0^{*}$ & $10^{*}$ \\
\hline
\end{tabular}

*Values indicate the minimum and maximum percentage of patients referred. COPD Chronic obstructive pulmonary disease

TABLE 4

Frequency distribution of item scores in the questionnaire

\begin{tabular}{|c|c|c|c|c|c|c|c|}
\hline & \multicolumn{7}{|c|}{ Score } \\
\hline & 0 & 1 & 2 & 3 & 4 & 5 & 6 \\
\hline $\begin{array}{l}\text { Sputum induction is a noninvasive usually successful and safe method to assess the type of } \\
\text { airway inflammation }\end{array}$ & 0.0 & 0.9 & 2.8 & 15.7 & 30.6 & 32.4 & 17.6 \\
\hline I am satisfied with the time required to get an appointment for sputum induction & 4.8 & 2.9 & 1.9 & 25.7 & 33.3 & 23.8 & 7.6 \\
\hline $\begin{array}{l}\text { I feel my patient understands the need to have a sputum test to assess the type of airway } \\
\text { inflammation than not to have one }\end{array}$ & 3.9 & 2.9 & 6.9 & 26.5 & 35.3 & 20.6 & 3.9 \\
\hline I usually receive the sputum report within 3 to 7 days after the procedure is done. & 4.8 & 2.9 & 10.6 & 27.9 & 20.2 & 26 & 7.7 \\
\hline I would like to receive the sputum report within a time frame of 3 days & 2.9 & 9.7 & 10.7 & 28.2 & 9.7 & 21.4 & 17.5 \\
\hline I understand the information that I get from this report & 1.9 & 0.9 & 5.6 & 15 & 30.8 & 32.7 & 13.1 \\
\hline I value the information that I get from this report & 1.0 & 1.9 & 3.8 & 11.5 & 26.0 & 35.6 & 20.2 \\
\hline The different types of airway inflammation are clear to me after reviewing the sputum reports & 1.9 & 3.7 & 11.2 & 23.4 & 29.9 & 20.6 & 9.3 \\
\hline Sputum induction provides me with information that I am unable to obtain clinically & 1.9 & 2.8 & 6.5 & 16.8 & 27.1 & 34.6 & 10.3 \\
\hline I feel I am achieving worthwhile results through my referral for sputum induction & 3.8 & 0.9 & 2.8 & 14.2 & 36.8 & 31.1 & 10.4 \\
\hline The sputum report usually assists in arriving at the best possible treatment for my patient & 1.9 & 0.0 & 6.6 & 13.2 & 37.7 & 31.1 & 9.4 \\
\hline I can use the results to help establish the minimum dose of corticosteroid required & 0.9 & 6.5 & 9.3 & 21.5 & 30.8 & 20.6 & 10.3 \\
\hline I recognize that the procedure is useful in managing asthma, COPD and chronic cough & 0.0 & 0.9 & 4.7 & 10.4 & 35.8 & 27.4 & 20.8 \\
\hline I think it is especially useful when the patient is uncontrolled or exacerbated & 0.0 & 1.9 & 2.8 & 12.3 & 24.5 & 31.1 & 27.4 \\
\hline $\begin{array}{l}\text { Monitoring of airway inflammation to guide corticosteroid treatment reduces exacerbations } \\
\text { and hospitalizations }\end{array}$ & 0.0 & 0.9 & 1.9 & 12.3 & 34 & 31.1 & 19.8 \\
\hline Sputum induction should be a part of routine management for patients with airway disease & 1.0 & 3.8 & 7.6 & 26.7 & 23.8 & 21 & 16.2 \\
\hline This procedure should be funded by the Ontario Health Insurance Plan & 2.0 & 0.0 & 2 & 11.8 & 17.6 & 26.5 & 40.2 \\
\hline
\end{tabular}

The table reports the percentage of physicians achieving scores of 0 to 6. COPD Chronic obstructive pulmonary disease

survey was the first to assesses patient and physician satisfaction with quantitative sputum cell counts.

The OHIP covers $\$ 79.35$ (technical component $\$ 49$, professional component $\$ 30.35$ ) for sputum induction, while the remaining is from hospital laboratory funds (\$20.80) and research funds. However, the Ontario Medical Association (OMA) recommends that OHIP pay $\$ 150$ for sputum induction. Given that $90 \%$ of the respondents were willing to pay $\$ 125$, the OMA is justified in the latter recommendation. The OMA tariff committee is awaiting approval by the Ministry of Health and Long-Term Care. British Columbia has a billing code. Quebec and
Alberta do not have a provincial billing code, but there is a local funding plan for the University of Laval (Quebec City, Quebec) and the University of Calgary (Calgary, Alberta). Eleven respondents were not willing to pay for sputum induction, although $46 \%$ were very satisfied with the test. The reasoning behind this requires further prospective evaluation. It may partly be due to limitations of the 'willingness to pay' tool. Although it is well validated (25), questions may be misunderstood and responses may be modified according to financial status.

The results from the family physician survey questionnaire revealed an overall sense of satisfaction with sputum induction and enabled the 
identification of certain areas of dissatisfaction. While the referring respirologist received the result within $24 \mathrm{~h}$, family physicians were dissatisfied with the delay of more than seven days to receive the report by mail. Because the family physician does not refer the patient directly for sputum cell counts, this delay does not affect the treatment of the patient; however, we are working on improving the efficiency of the program toward simplifying and automating the test so that a physician outside of our hospital can also receive the report within $24 \mathrm{~h}$, which is crucial to adjust treatment, especially during an exacerbation. The other issues can be addressed by ensuring that clear clinical advice based on the sputum cell count is included in the report sent to the physicians.

Although the cell counts provide an accurate assessment of cellular bronchitis, it is not available as a point-of-contact test that enables physicians to make adjustments to treatments at the time of a patient's clinic visit. Although this is not a major limitation, it is widely perceived as a drawback. A more reasonable limitation is the difficulty in establishing a laboratory that is capable of performing this test. Although cell counts can be performed in a any core laboratory that is staffed by medical laboratory technologists trained in cellular morphology, similar to any other laboratory procedure, this requires regular quality control and training. Another major reason that the test is not widely used, at least in Canada, is the lack of a fee reimbursement system to compensate for the provision of a clinical service.

\section{REFERENCES}

1. Hargreave FE, Parameswaran K. Asthma, COPD and bronchitis are just components of airway disease. Eur Respir J 2006;28:264-7.

2. Anderson GP. Endotyping asthma: New insights into key pathogenic mechanisms in a complex, heterogeneous disease. Lancet 2008;372:1107-19.

3. Bel EH, Sousa A, Fleming L, et al. Diagnosis and definition of severe refractory asthma: An international consensus statement from the innovative medicine initiative (IMI). Thorax 2011;66:910-7.

4. Bousquet J, Mantzouranis E, Cruz AA, et al. Uniform definition of asthma severity, control, and exacerbations: Document presented for the World Health Organization consultation on severe asthma. J Allergy Clin Immunol 2010;126:926-38.

5. Taylor DR, Pijnenburg MW, Smith AD, De Jongste JC. Exhaled nitric oxide measurements: Clinical application and interpretation. Thorax 2006;61:817-27.

6. Brightling CE. Clinical applications of induced sputum. Chest 2006;129:1344-8.

7. O'Byrne PM, Parameswaran K. Pharmacological management of mild or moderate persistent asthma. Lancet 2006;368:794-803.

8. Brightling CE. Chronic cough due to nonasthmatic eosinophilic bronchitis: ACCP evidence-based clinical practice guidelines. Chest 2006;129(1 Suppl):116S-21S

9. Hargreave FE. Quantitative sputum cell counts as a marker of airway inflammation in clinical practice. Curr Opin Allergy Clin Immunol 2007;7:102-6.

10. Shaw DE, Berry MA, Thomas M, et al. The use of exhaled nitric oxide to guide asthma management: A randomized controlled trial. Am J Respir Crit Care Med 2007;176:231-7.

11. Jayaram L, Pizzichini MM, Cook RJ, et al. Determining asthma treatment by monitoring sputum cell counts: Effect on exacerbations. Eur Respir J 2006;27:483-94.

12. D'silva L, Gafni A, Pizzichini M. The costs of using sputum cell counts in asthma management, 2007 (Abstract 29). American Thoracic Society Poster Discussion, San Francisco, May 2007.

13. Peters SP. Counterpoint: Is measuring sputum eosinophils useful in the management of severe asthma? No, not for the vast majority of patients. Chest 2011;139:1273,5.
The use of quantitative sputum cell counts to guide treatment in airway disease is more effective (11) and less costly than traditional management using symptoms and spirometry (12), causes minimal discomfort to the patient and is, therefore, acceptable to patients. This is particularly important when repeat testing is required to monitor disease. Physicians also revealed an overall sense of satisfaction with the use of the test in clinical practice, providing they could receive the result more promptly and were in favour of the test being funded by OHIP. Now that billing codes are available, the procedure is feasible, practical and available in Quebec City, Montreal, Hamilton and Calgary, and it is time to implement quantitative sputum cell counts into routine clinical practice in all centres managing patients with airways disease.

ACKNOWLEDGEMENTS: LD was involved in study design, acquired data and produced the first draft of the manuscript. HN critically revised the manuscript. AG contributed to research design and data analysis. KR contributed to research design and data acquisition. PN designed the study and critically revised the manuscript.

DISCLOSURES: Dr Nair is supported by a Canada Research Chair in Airway Inflammometry. Dr D'silva was supported by a Merck Frosst Canada Educational Fellowship. This study was funded, in part, by a Hamilton Community Foundation Grant.

14. Nair P, Hargreave FE. Measuring bronchitis in airway diseases: Clinical implementation and application: Airway hyperresponsiveness in asthma: Its measurement and clinical significance. Chest 2010;138(2 Suppl):38S-43S.

15. Speight J, Barendse SM. FDA guidance on patient reported outcomes. BMJ 2010;340:c2921.

16. Chow A, Mayer EK, Darzi AW, Athanasiou T. Patient-reported outcome measures: The importance of patient satisfaction in surgery. Surgery 2009;146:435-43.

17. van Campen C, Sixma H, Friele RD, Kerssens JJ, Peters L. Quality of care and patient satisfaction: A review of measuring instruments. Med Care Res Rev 1995;52:109-33.

18. Hadji P. Improving compliance and persistence to adjuvant tamoxifen and aromatase inhibitor therapy. Crit Rev Oncol Hematol 2010;73:156-66.

19. Kraai IH, Luttik ML, de Jong RM, Jaarsma T, Hillege HL. Heart failure patients monitored with telemedicine: Patient satisfaction, a review of the literature. J Card Fail 2011;17:684-90.

20. Leung GM, Ho LM, Chan MF, M Johnston JM, Wong FK. The effects of cash and lottery incentives on mailed surveys to physicians: A randomized trial. J Clin Epidemiol 2002;55:801-7.

21. Kaner EF, Haighton CA, McAvoy BR. 'So much post, so busy with practice - so, no time!': A telephone survey of general practitioners' reasons for not participating in postal questionnaire surveys. Br J Gen Pract 1998;48:1067-9.

22. Heiner MM. Key barriers to optimal management of adult asthma in Australia: Physician and patient perspectives. Curr Med Res Opin 2007;23:1799-807.

23. Kennedy WA, Girard F, Chaboillez S, et al. Cost-effectiveness of various diagnostic approaches for occupational asthma. Can Respir J 2007;14:276-80.

24. Barr RG, Celli BR, Martinez FJ, et al. Physician and patient perceptions in COPD: The COPD Resource Network Needs Assessment Survey. Am J Med 2005;118:1415.

25. Donaldson C, Hundley V, Mapp T. Willingness to pay: A method for measuring preferences for maternity care? Birth 1998;25:32-9. 


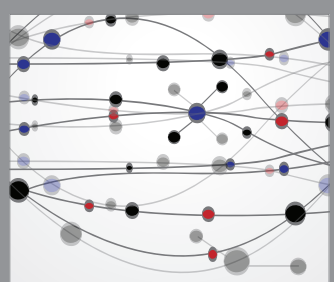

The Scientific World Journal
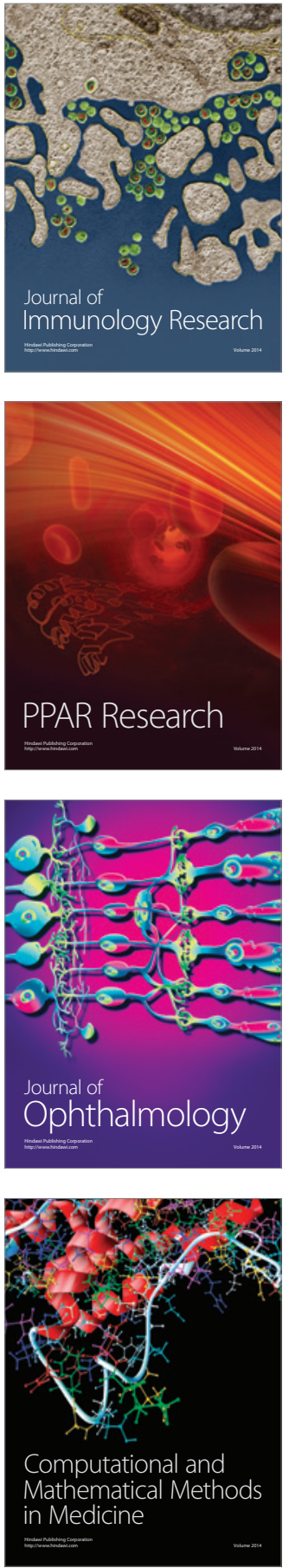

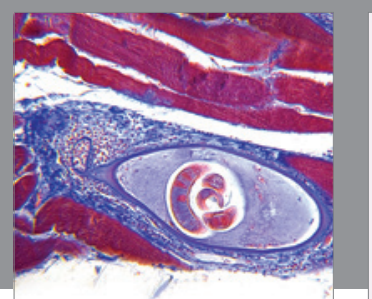

Gastroenterology Research and Practice

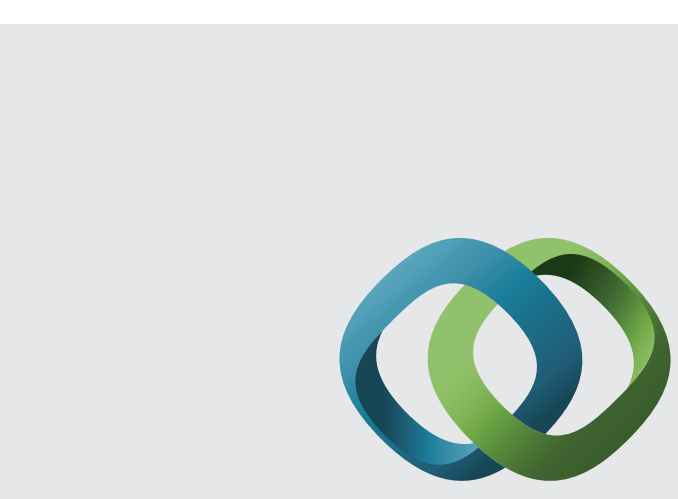

\section{Hindawi}

Submit your manuscripts at

http://www.hindawi.com
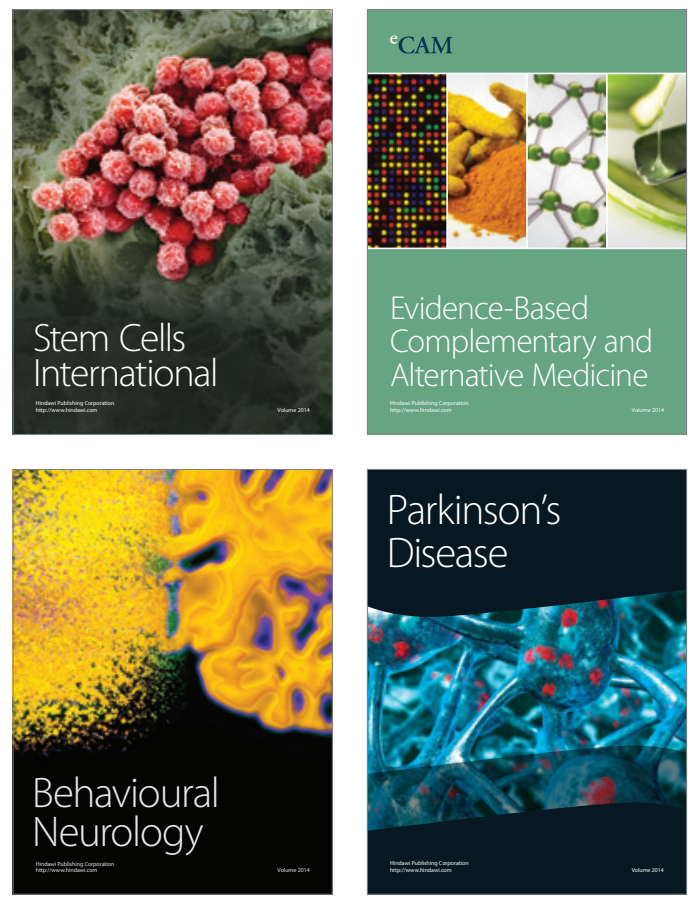
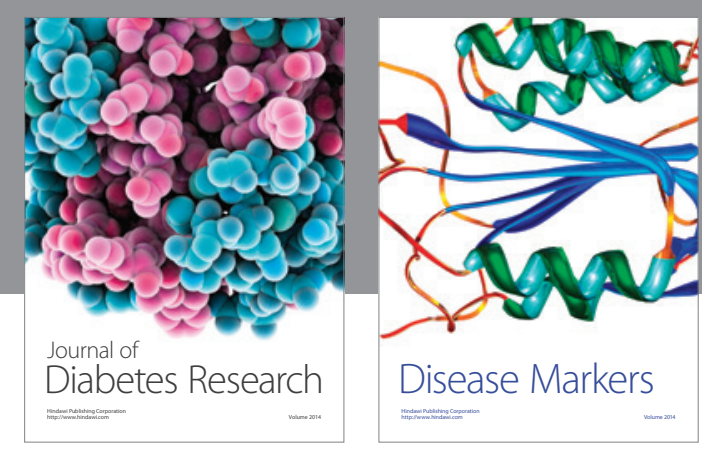

Disease Markers
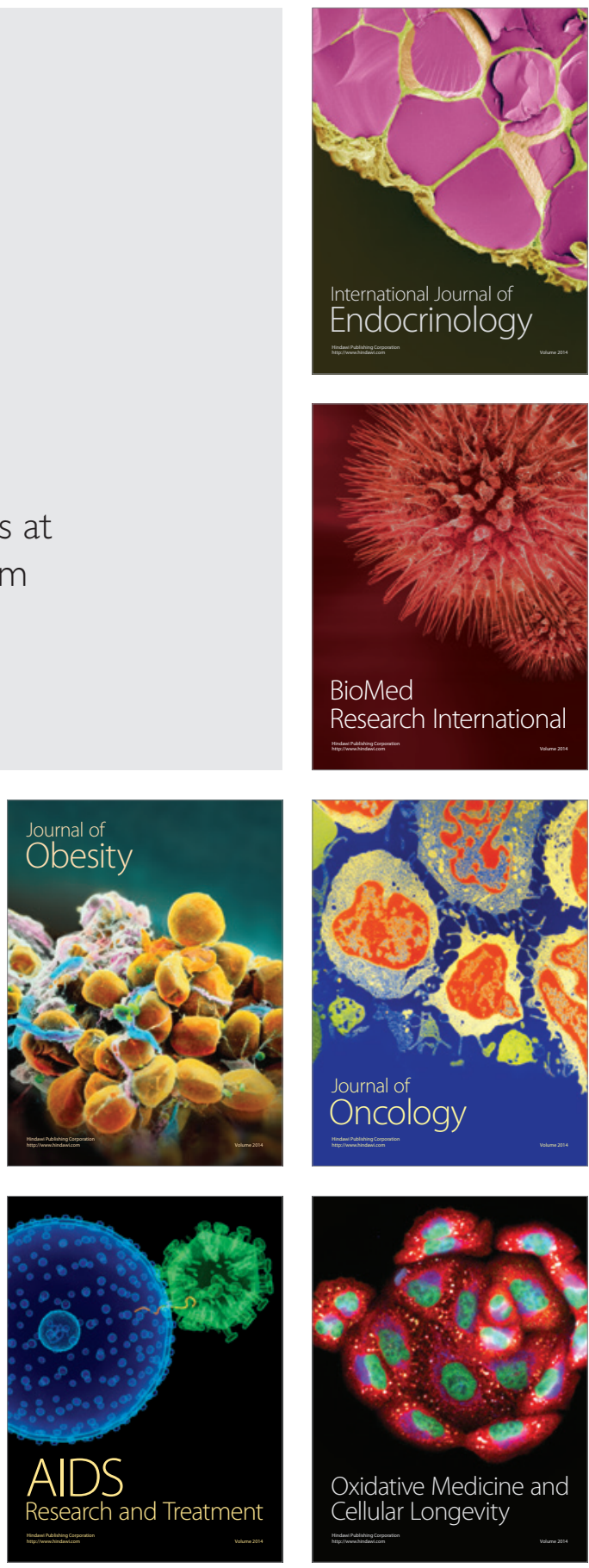